\title{
The Epidemio-Clinic Profile of Clandestine Abortion at Saint Joseph Hospital (Kinshasa)
}

\author{
Leon Mubikayi', Aristide Yamba1, Yannick Mubikayi', Elisee Kuedimutshima², \\ Dolores Nembunzu ${ }^{3}$
}

${ }^{1}$ School of Medicine, Kasayi University, Kananga, Democratic Republic of the Congo

${ }^{2}$ Nurse School of Kananga, Kananga, Democratic Republic of the Congo

${ }^{3}$ Saint Joseph Hospital, Kinshasa, Democratic Republic of the Congo

Email: leonmubi@yahoo.fr

How to cite this paper: Mubikayi, L. Yamba, A., Mubikayi, Y., Kuedimutshima, E. and Nembunzu, D. (2018) The Epidemio-Clinic Profile of Clandestine Abortion at Saint Joseph Hospital (Kinshasa). Open Journal of Obstetrics and Gynecology, 8, 1176-1184.

https://doi.org/10.4236/ojog.2018.812119

Received: August 30, 2018

Accepted: October 16, 2018

Published: October 19, 2018

Copyright $\odot 2018$ by author and Scientific Research Publishing Inc. This work is licensed under the Creative Commons Attribution International License (CC BY 4.0).

http://creativecommons.org/licenses/by/4.0/

\section{(c) (i) Open Access}

\begin{abstract}
Objective: To identify the epidemiologic profile of the woman having practiced the clandestine abortion, to determine the frequency and the complications of the clandestine abortion and to evaluate the prognosis of the clandestine abortion in our area. Method: The present study is descriptive and retrospective covering the period from January 2017 to December 2017, the one year period. On 118 patients received in the service for clandestine abortion, 60 were retained for the study. The 58 other files were excluded because of not containing sufficient information for this study. The descriptive statistical analyses were applied for the data analysis. Results: The frequency of the allowed patients for complication of clandestine abortion caused at the Saint Joseph hospital of Kinshasa was $6.03 \%$. The most concerned population with this practice was less than 15 years and more than 45 years; they were unmarried (41.6\%) and nulliparous (41.6\%) in most cases. Ancillary medical staff (especially nurses) was accused the most in this practice of the illegal abortion caused by the dilatation and curettage with $50 \%$. The genital haemorrhage constitutes the principal complication and reason for consultation and accounted for $78.3 \%$. The assumption of responsibility is primarily medical and surgical. The vital prognosis is satisfactory for the immediate one, because no death is noted. Conclusion: The clandestine abortion remains public health problem in our communities. The results found in our study call for certain reflections so that to reduce its frequency and to avoid its complications.
\end{abstract}

\section{Keywords}

Abortions, Clandestine, Complications 


\section{Introduction}

The abortion is an old method of regulation of the fertility which existed and was used well before the appearance of the contraceptive methods [1]. According to FIGO and WHO, the abortion is the expulsion of ovular products weighing less than 500 grams or failing this, of ovular products of less than 22 weeks of amenorrhoea [2]. The clandestine abortion was and remains public health problems in the whole world in general and especially in the countries in the process of development in particular.

It constitutes an important cause of maternal mortality. According to WHO [2], a few 42 million abortions were practiced in the world in 2003 and $20 \%$ of the pregnancies were stopped in a caused way. Twenty million abortions at the risk take place each year in the world and are responsible for 78,000 maternal deaths. According to WHO [3] [4] the abortion at the risk is defined like: "an intervention aiming at stopping an undesired pregnancy often by people who do not have necessary competences, that is to say in a context where the minimal sanitary arrangements do not exist or both.

Besides maternal deaths, the abortions at the risk are responsible for a strong morbidity at $10 \%$ to $20 \%$ of the women, infertility, the hypofertility, the chronic pelvic pains, extra-uterine pregnancy, the miscarriages, the premature births, and even of the psychic after-effects [5] [6]. In DRC, the Congolese law prohibited the abortion. The therapeutic abortion is possible according to article 32 of the Code of conduct medical [7].

Our work has as general objective to identify the profile epidemio-clinic of the clandestine abortions received at the Saint Joseph Hospital of Kinshasa.

Specific objectives

To determine the frequency of the abortion caused in our area,

$>$ To identify the complications of the clandestine and unsafe abortion,

To evaluate the prognosis of the woman victim of the clandestine abortion.

\section{Patients and Methods}

We conducted a descriptive, retrospective and transverse study, covering the period from January 2017 to December 2017 at the Saint Joseph Hospital of Kinshasa. Our sample is exhaustive on all folders of clandestine abortions caused in the study area.

Back up included in the study, the patients with clandestine and unsafe abortions in the study area.

All the others patients apart from this criterion were not considered for the studied parameters. The data were collected starting from the registers of admission of emergency department of obstetrics gynaecology, as well as the clinical files of the patients. The induced abortion is not legally accepted in the Democratic Republic of the Congo, so this practice is doing in the clandestine way and called clandestine abortion.

The collected interest variables were the age, the parity, the gestity, the educational level, the profession, the Marital status, the quality of the abortionist, the 
average abortive one used, the symptoms required at the consultation, the number of former abortions, the complications and the assumption of responsibility. The descriptive statistical analyses were applied to analyze the data.

Operational definitions

The parity: it is the number of childbirth of pregnancies having reached the age of viability.

Gestity: is the number of pregnancies which the woman carried.

\section{Results}

During the study period, 1956 patients were admitted in Ob/Gyn service, among whom, 118 patients consulted for the complications of clandestine abortion, a frequency of $6.03 \%$. In addition, of these 118 files of the patients, only 60 comprehensive directories helped us to make our study.

It is deduced from Table 1 that the most concerned age was from 25 to 29 years old with $25 \%$.

It comes out from Figure 1 that most patients were unmarried with $41.6 \%$.

It comes out from Figure 2 that most patients had a primary level with 73.3\%.

Most patients having consulted for complications of clandestine abortion were housewives, $75 \%$ (Figure 3).

The nulliparous ones were most concerned in our study with 25 cases with $41.6 \%$ (Figure 4 ).

The paucigestes had represented $45 \%$ of cases (Table 2).

It is deduced from this Table 3 that the caused abortion was practised in the majority of the cases by the ancillary medical with $50 \%$.

We noted that the dilatation and curettage was the more used means with 30 cases (50\%) (Table 4).

The genital haemorrhage is the reason for consultation in most cases $(58.3 \%)$ (Figure 5).

It is deduced from this Table 5 that $75 \%$ of patients have already at least an antecedent of clandestine abortion.

The genital haemorrhage represents the largest complication with $78.3 \%$ (Table 6).

It comes out from this Figure 6 that in most case may be 56.7\%, association Quinolones and imidazoles was used.

Table 1. Distribution of the patients according to the age.

\begin{tabular}{ccc}
\hline Age (year) & $\mathrm{n}$ & $\%$ \\
\hline$\leq 15-19$ & 8 & 13.3 \\
$20-24$ & 11 & 18.3 \\
$25-29$ & 15 & 25 \\
$30-34$ & 9 & 15 \\
$35-39$ & 10 & 16.7 \\
$\geq 40$ & 7 & 11.7 \\
\hline
\end{tabular}




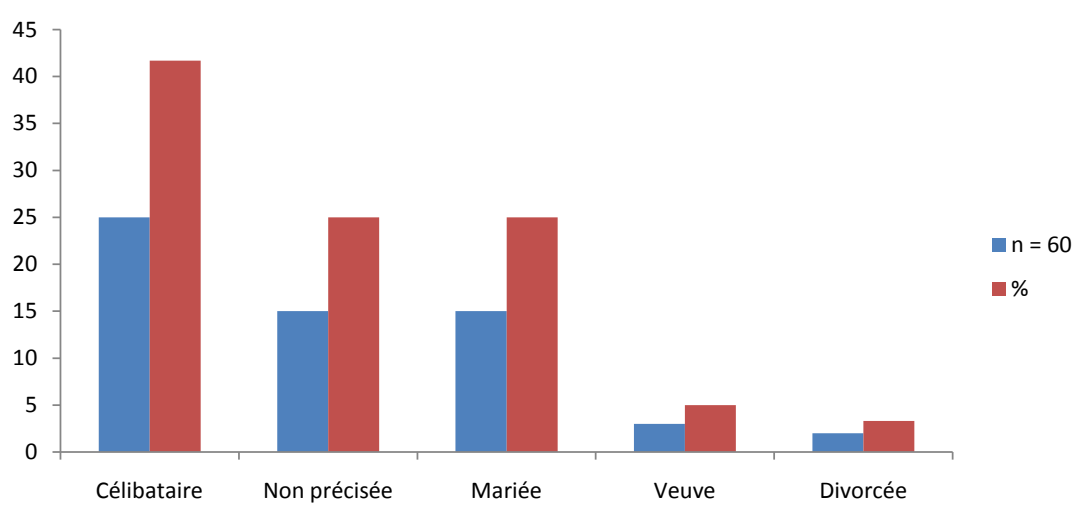

Figure 1. Distribution of the patients depending on the Marital status.

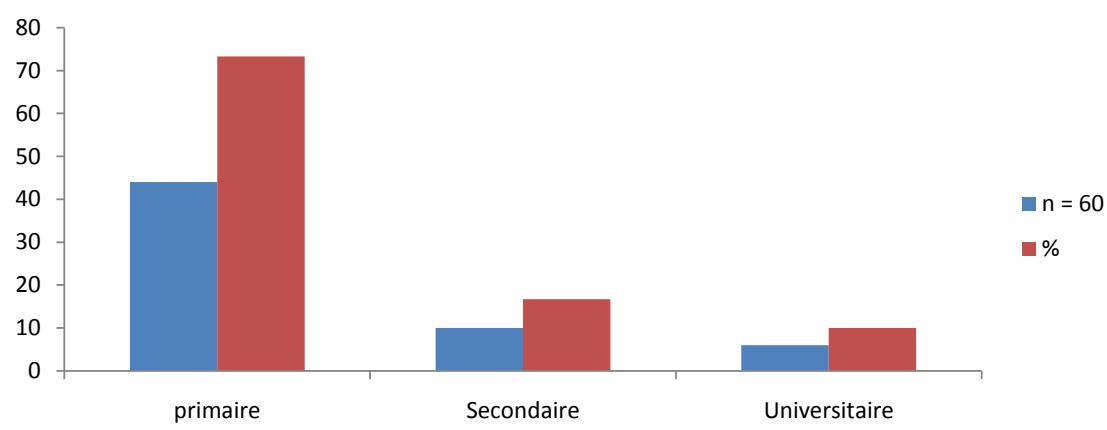

Figure 2. Distribution according to the educational level.

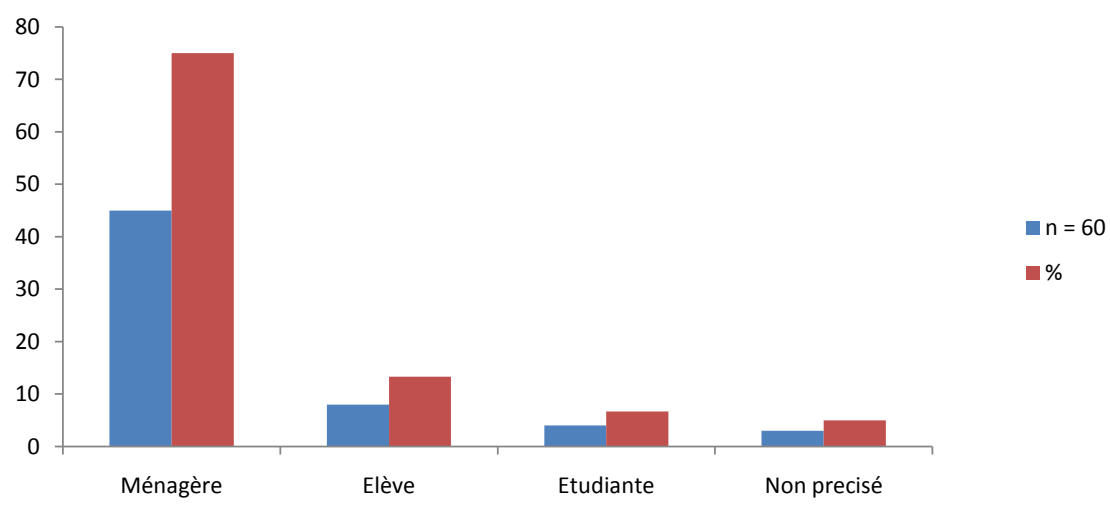

Figure 3. distribution according to the profession.

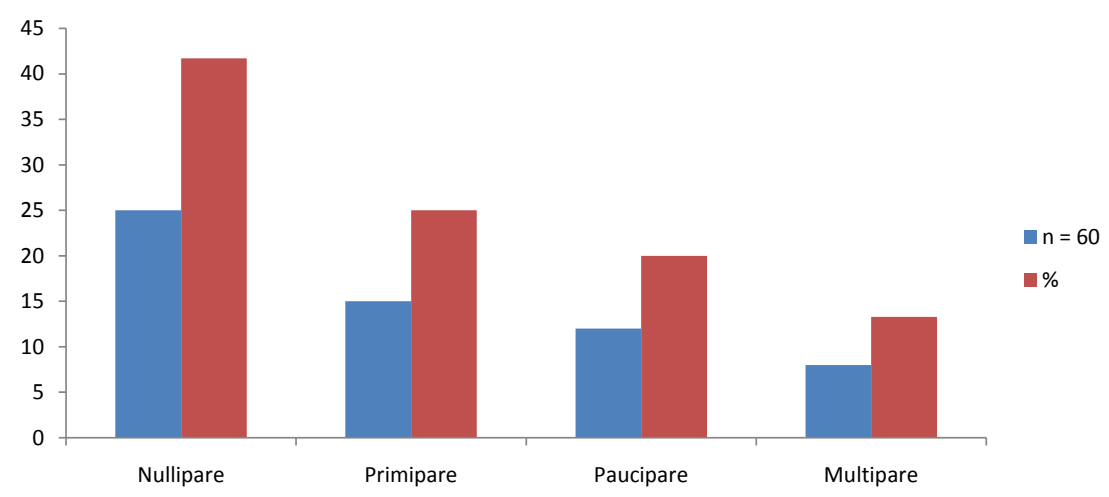

Figure 4. Distribution according to the parity. 
Table 2. Distribution according to the gestity.

\begin{tabular}{ccc}
\hline Gestity & $\mathrm{n}$ & $\%$ \\
\hline Primigeste & 20 & 33.3 \\
Paucigeste & 27 & 45 \\
Multigeste & 13 & 21.7 \\
\hline
\end{tabular}

Table 3. Distribution according to the quality of the abortionist.

\begin{tabular}{ccc}
\hline Quality of the abortionist & $\mathrm{n}$ & $\%$ \\
\hline Not specified & 1 & 1.7 \\
Medical Doctor & 9 & 15 \\
Herself & 20 & 33.3 \\
Ancillary medical & 30 & 50 \\
\hline
\end{tabular}

Table 4. Distribution according to the means used.

\begin{tabular}{ccc}
\hline Average abortive & $\mathrm{n}$ & $\%$ \\
\hline Curettage & 30 & 50 \\
Uterotonics & 10 & 16.7 \\
Not specified & 20 & 33.3 \\
\hline
\end{tabular}

Table 5. Distribution according to the former abortion.

\begin{tabular}{ccc}
\hline Former abortion & $\mathrm{n}$ & $\%$ \\
\hline Spontaneous & 15 & 25 \\
Clandestine & 45 & 75 \\
\hline
\end{tabular}

Table 6. Distribution according to the complications met.

\begin{tabular}{ccc}
\hline Complications & $\mathrm{n}$ & $\%$ \\
\hline Hemorrhagic shock & 47 & 78.3 \\
Infection & 7 & 11.7 \\
Lesions of the soft parts (vagina and uterus) & 6 & 10 \\
\hline
\end{tabular}

Most patients, 90\% profited from a dilatation and curettage (Figure 7).

\section{Discussion}

The clandestine abortion remains public health problems in our areas. The results found in our study call for certain reflections to reduce its frequency and to avoid its complications.

The frequency of patients admitted for complications of clandestine abortion caused at the Saint Joseph Hospital of Kinshasa was $6.03 \%$. In this study, the most important age lies between 25 - 29 years. Our results join those of VANGA [8] at Kinshasa in 2010, RASH [9] at Tanzania in 2006, GUILLAUME [10] at 


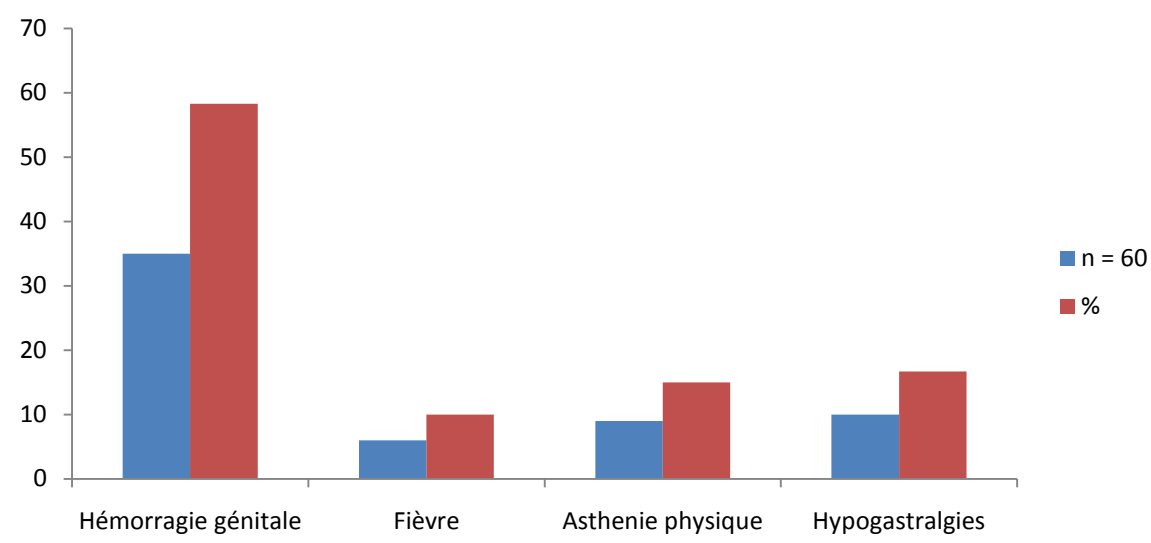

Figure 5. Distribution according to the reasons of the consultation.

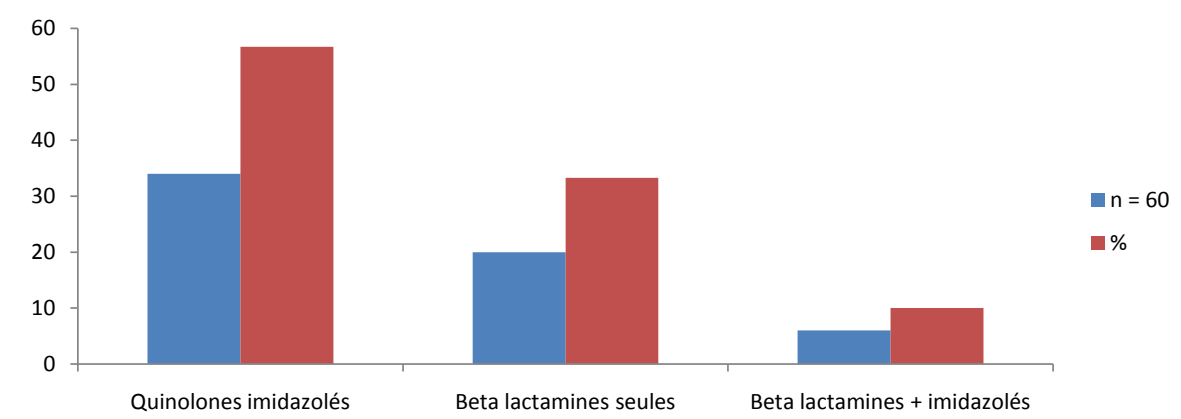

Figure 6. Distribution according to the medical care.

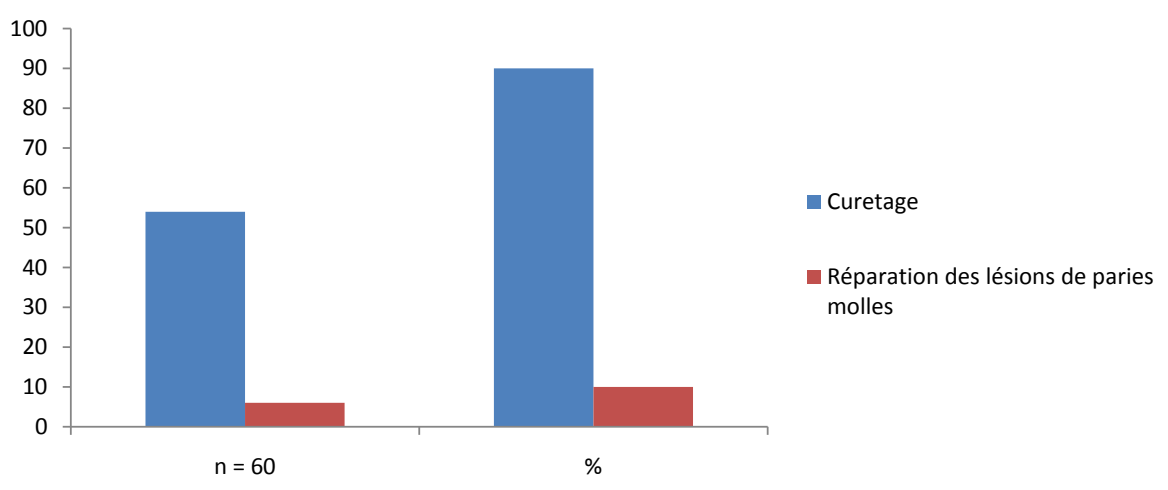

Figure 7. Distribution according to the surgical treatment.

Ivory Coast in 1999 and TRAORE CHEICK [11] at Bamako in 2010. This may be explained by the fact why it is the age where the young girls are sexually very active. Besides that, some are still pupils or students and live under the paternal house, out of fear of being returned house, and shame to be unmarried mother with the undesired pregnancy and continue the studies, they resort to this very dangerous practice. However, NTABONA [12] at Kinshasa in 1980, DIKAMBA [13] at Kinshasa in 2010 and ZAMUDIO [14] at Colombia in 2000, found an age bracket lower than ours, 15 - 19 ans.

It comes out from our study that $41.6 \%$ of patients were single people, this was also found by GUILLAUME and DESGRESS DELOU [10] in 1999 in Ivory 
Coast, MAYI TSONGA [15] at Libreville in 2008, NTAMBONA [12] at Kinshasa in 1980, DIKAMBA [13] at Kinshasa in 2010 and VANGA [8] at Kinshasa in 2010. Many studies proved that they are the unmarried women who have more recourse to this practice of the clandestine abortion because of the undesired pregnancy [1] [4] [5] [16].

Noted in our study that most patients had a primary level of study. Our results join those of the certain authors who found that the low educational level constitutes a risk factor of clandestine abortions [17]. On the other hand, TRAORE [11] at Bamako in 2004 in his series, found that the women with secondary and university level are concerned with the practice of the illegal abortion. This is explained because in our areas, the young girls are not encouraged to go to school.

Most the patients were the housewives (without profession). This result is close to that of GUESSAN [17] and VANGA [8] at Kinshasa in 2010. On the other hand, NTAMBONA [12] at Kinshasa in 1980 and DIKAMBA [13] at Kinshasa in 2010; in their series, found that most the patients were schoolgirls and student. This is explained by the fact of the unemployment in this Country, the Democratic republic of Congo (DRC).

In our study, noted that most women who consulted for complications of clandestine unsafe abortions were the nulliparous ones, $41.1 \%$. These results join those of NTABONA [12] in Kinshasa in 1980, DIKAMBA [13] at Kinshasa in 2010, TRAORE [11] at Bamako in 2010. The reason, it is fear to have a child out of the marriage, to be rejected by the family, and bad socio-economic conditions. Many patients, $45 \%$ were paucigestes. We noted a divergence on the gestity in various studies. DIKAMBA and VANGA had found that most patients were primigestes, this can be explained by the size of their sample and their duration of study.

In most case, $33.3 \%$, the ancillary medical ones are at the base of interruption of the pregnancies. Our results join those of NTABONA [12] at Kinshasa in 1980, ILOKI [16] at Brazzaville in 1967, DIKAMBA [13] at Kinshasa in 2010 and VANGA at Kinshasa in 2010 [8]. On the other hand, MAYI TSONGA [15] at Libreville in 2008 had found that the most practiced self-medication. We think that this difference can be due to our various areas of studies. Abortive method the most practiced in $50 \%$ of case was dilatation and curettage, followed by the self-medication with $16.7 \%$. Our results join those of NTABONA [12] at Kinshasa in 1980, DIKAMBA [13] at Kinshasa in 2010 and GUESSAN [17] in 2004 which also found that the dilatation and curettage was the most used method for illegal abortion respectively practiced $41.53 \%, 66 \%$ and $62.39 \%$.

On the other hand, VANGA (18) at Kinshasa 2010 and MAYI TSONGA [15] at Libreville in 2008 had found in their studies the use of the misoprostol. We think that this difference is due to the sample, small for us and large for them. In the present study, the genital haemorrhage constitutes the principal reason for consultation either $58.3 \%$, followed by physical asthenia with $15 \%$ and the fever 
accounted for $10 \%$.

Our results join those of DIARRA DIABATE [18] at Mali in 2000, NTABONA [12] at Kinshasa in 1980, DIKAMBA [13] at Kinshasa in 2010 and VANGA [8] at Kinshasa in 2010. For all these authors the genital haemorrhage remains the principal reason for consultation after clandestine abortion. Among the complications met, the genital haemorrhage is the complication most met in $78.3 \%$, followed by the infections with $11.7 \%$ and finally the lesions of the soft parts with $10 \%$. Our results join those of MAYI TSONGA [15] at Libreville into 2008 and VANGA [8] at Kinshasa in 2010 which had found that the haemorrhage passed in first position in respectively $55.9 \%$ and $61.6 \%$.

On the other hand, DIKAMBA [13] at Kinshasa in 2010 found that the infections passed in first position are 58.5\%. They were come to the lack of asepsis which characterizes the clandestine abortions caused by dilatation-curettage. In our study, most patients profited from a dilatation and curettage, under general anesthesia with $90 \%$ of cases and some antibiotics. Our results join those of the other authors who, in their studies found that the medico-surgical assumption of responsibility was practiced for the care of the complications of the clandestine abortions, DIKAMBA [13] at Kinshasa in 2010 and VANGA [8] at Kinshasa in 2010. No death was noted in our study, all the patients left the hospital healed.

\section{Conclusion}

The clandestine abortion remains a public health problem in our area. The results found in our study call for certain reflections for so much or little to reduce its frequency and to avoid its complications. Thus, the information and the sensitizing of the population and the health workforce on this plague are of a major importance for the wellness of the woman.

\section{Conflicts of Interest}

The author declares no conflicts of interest regarding the publication of this paper.

\section{References}

[1] Mc Laren, A. (2011) A History of Contraception. From Antiquity to the Present Day. Black Well Oxford, Cambridge, 275.

[2] WHO/HRP (2006) Progress of Sexual and Genesic Health. WHO, New York, 73.

[3] World Health Organization (2004) Unsafe Abortion. Total and Regional Estimates of Unsafe Abortion and Associated Mortality in 2000. 4th Edition, WHO, Geneva, 82.

[4] Kitenge, K.K.C. (2009) Gynaecological Pathologies in Relation to Gestation. Medical Congo, 59, 61-70.

[5] The United Nations (1996) Report of the Fourth World Conference on the Women. The United Nations, New York, 12.

[6] The United Nations (1995) Report of the International Conference on Population and the Development. The United Nations, New York, Number of Sale: 95. XIII.18. 
[7] Ministry for Justice (1940) Penal Code of the Democratic Republic of Congo. Ministry for Justice, Kinshasa, 42.

[8] Vanga, G. (2010) Cases of Clandestine Abortions in the Hospitals of Reference of Kinshasa. Med Congo, 61, 45-8.

[9] Rash, V., et al. (2006) Unsafe Abortion in Urban and Rural Tanzania: METHOD provider and Consequences. Tropical Medicine and International Health, 14, 1128-1133. https://doi.org/10.1111/j.1365-3156.2009.02327.x

[10] Guillaume, A. (2004) The Abortion Caused in Africa: A Badly Known, Full Problem of Consequence. Pulpit Quetect, Paris, 1-3.

[11] Traore, A.K. (2004) Abortions at the Risk at the Reference Health Center of Point V of Bamako from May 2001 to May 2003 about 134 Cases. Thesis, Med., Bamako, 8: 77.

[12] Ntabona (1980) Some Clinical and Social Aspects of the Abortions at Kinshasa. Medical Congo, Kinshasa.

[13] Dikamba, N.R. (2010) Multicentric Study of the Determinants and the Complications of the Clandestine Abortions in the Reference Hospitals of Kinshasa. Medical Congo, Kinshasa.

[14] Rubiano, Z. (2000) Effect of the Voluntary Abortion on the Reduction of the Descent in Colombia, Controls Fertility and Family Planning in the South. Journal of Family Planning, 94, 60-61.

[15] Mayi Tsonga, S. (2008) Prevalence of the Clandestine Abortions at the Hospital of Libreville. Med of black Africa, 2, 328-331.

[16] Iloki, A., Zakouloulou, M. and Gbala, S. (1967) Complications of the Clandestine Abortions: About 201 Cases Observed with the University Hospital from Brazaville (Congo). Medicine of Black Africa, 44, 5.

[17] Guessan, K., Doumbia, Y., Kakou, C. and Adjoby, R. (2004) Uterine Perforations during Abortions. Medicine of Black Africa, 54, 169-173.

[18] Diarra, I. (2008) The Abortion Caused about 180 Cases at the Hospital Gabriel and Touré. Medical Mali, XXIII, 432-438. 